\title{
Metodoloxía para a integración dos servizos ecosistémicos dos montes veciñais en espazos naturais no seu plan de ordenación e xestión: unha aproximación dende a arqueoloxía e o patrimonio cultural
}

\author{
Methodology for integration and management of ecosystem services of commonly held \\ mountain in natural spaces: an approach from archaeology and cultural heritage \\ SAMUEL NIÓN ÁLVAREZ \\ Síncrisis, Investigación en Formas Culturais. Departamento de Historia, \\ Universidade de Santiago de Compostela \\ https://orcid.org/0000-0001-9717-2383 \\ samuelnionalvarez@gmail.com \\ JORGE M. BLANCO BALLÓN \\ Asociación de Desenvolvemento Rural Mariñas-Betanzos \\ xerencia@marinasbetanzos.gal \\ MANUEL GIMÉNEZ SOLLA \\ Asociación de Desenvolvemento Rural Mariñas-Betanzos \\ xerencia@marinasbetanzos.gal \\ JUAN CASTRO ÍNSUA \\ Centro de Investigación Agraria de Mabegondo, Instituto Galego de Calidade Alimentaria \\ juan.fernando.castro.insua@xunta.gal \\ MANUEL CANDAL SEIJAS \\ Monte Veciñal en Man Común Xalo \\ montecomunalxalo@gmail.com
}

\section{Resumo}

O obxectivo desta publicación é dar a coñecer unha proposta metodolóxica multidisciplinar para a xestión e planificación dos usos e aproveitamentos do monte Xalo (Culleredo, A Coruña) no que se integren os valores dos servizos ecosistémicos producidos, amosando ademais un dos procedementos de actuación dunha das disciplinas integradas: a arqueoloxía e o patrimonio cultural. Esta iniciativa xeral foi definida por un Grupo Operativo de Innovación formado por entidades de distintos 
perfís que gardan relación co desenvolvemento rural do ámbito das da Reserva da Biosfera Mariñas Coruñesas e Terras do Mandeo (CMVMC Xalo, Asociación de Desenvolvemento Rural MariñasBetanzos, USC, Ingacal, IET) na provincia da Coruña, e que optan por aplicar novas directrices que promovan un modelo de xestión sostible.

Desta forma, esta publicación exporá en primeiro lugar o marco do proxecto e os seus postulados principais, pasando a centrarse posteriormente no procedemento de actuación plantexado pola arqueoloxía e o patrimonio cultural, unha das disciplinas integradas que non adoita ser unha parte relevante dentro da xestión habitual dos recursos forestais.

Palabras clave: Monte Xalo, monte veciñal en man común, multifuncionaidade do monte, xestión sostible, arqueoloxía e patrimonio cultural.

\begin{abstract}
The aim of this paper is to state a methodological proposal to manage and plan the uses of commonly held mountains, using as a pilot area the commonly held mountain of Monte Xalo (Culleredo, A Coruña) and focusing on action procedures of archaeology an cultural heritage, one of the integrated disciplines. This initiative was designed by an innovation Operative Group, formed by miscellaneous entities related to the rural development of the so called region "Mariñas Coruñesas". This proposal will not put on the usual approaches of customary methodologies for the forest ordination and management, but use new guidelines which would boost a new sustainable model of forest management. These new criteria will allow the compatibilization of logging exploitation with other environmental, social or cultural services related to the mount.

Thus, this paper is conceived as a statement for the inicial proposals, methodologies and objectives developed in this project. Finally, we will focus on the methodological strategies of cultural heritage, a matter that is usually ignored in the management of forest resources.
\end{abstract}

Keywords: Monte Xalo, commonly held mountain, mountain multifunctionality, sustainable management, archaeology and cultural heritage.

\title{
1. INTRODUCIÓN
}

Galicia é a principal rexión produtora madereira de España: máis do 50\% do volume de cortas de madeira con destino industrial realizados a nivel estatal proveñen do territorio galego (atendendo ao Anuario de Estatística Forestal (Ministerio de Agricultura y Pesca, Alimentación y Medio Ambiente, 2017)). De forma paralela, durante os últimos anos foron aprobadas unha inxente cantidade de medidas lexislativas no sector forestal a nivel autonómico, creando unha base xurídica que simplifica e clarifica moitos dos procesos e xestións habituais que gardan relación cos terreos forestais (entre outras, destacamos: Lei 7/2012, de 28 de xuño de montes de Galicia (2012); Decreto 50/2014, do 10 de abril, polo que se regulan os aproveitamentos madeireiros e leñosos, de cortiza, pastos e micolóxicos en montes ou terreos forestais; Decreto 52/2014, do 16 de abril, polo que se regulan as instrucións xerais de ordenación e de xestión de montes de Galicia; Orde do 19 de maio de 2014 pola que se establecen os modelos silvícolas ou de xestión forestal). 
Aínda que os principios teóricos nos que se inspira esta normativa son os de potenciar a multifuncionalidade dos montes, a conservación e mellora dos recursos forestais, a calidade paisaxística ou o mantemento da biodiversidade; o certo é que a súa principal orientación céntrase na maximización da produción de madeira.

En pleno século XXI, nun escenario de sobreprodución e estancamento de prezos, cunha paisaxe cada vez máis erosionada e afectada por factores coma o cambio climático ou os incendios forestais, precísase que os montes integrados en áreas naturais teñan unhas directrices complementarias que propoñan e promovan un modelo de xestión forestal con criterios baseados nun aproveitamento madeireiro no que se coñezan os servizos ambientais producidos polo monte (biodiversidade, paisaxe, patrimonio cultural, uso social do monte, posibilidades de creación de emprego rural, fixación de emisións de $\mathrm{CO} 2$, recarga de acuíferos, etc.) ao mesmo tempo que permitan a súa compatibilidade. Como apoio, existe un amplo elenco de acordos internacionais (Convenio da Diversidade Biolóxica, Convenio do Cambio Climático, Convenio Europeo da Paisaxe, etc.) así como unha ampla lexislación a nivel europeo, estatal e autonómico que promoven a protección e conservación dos compoñentes do patrimonio natural e cultural, ao mesmo tempo que fomentan o desenvolvemento sustentable e promoven a súa integración na ordenación das áreas forestais.

Nos últimos anos os estudos que analizan os servizos prestados polos ecosistemas comezan a cobrar importancia, entendendo estes como a multitude de beneficios que estes aportan á sociedade e ao benestar humano (FAO, 2013; TEEB, 2009). A crecente poboación humana está sometendo á biodiversidade a unha enorme presión (destrución de hábitats, especies invasoras, sobreexplotación, contaminación, cambio climático, etc.) (Unión Internacional para la Conservación de la Naturaleza, 2018). Este declive nos hábitats naturais e na saúde dos ecosistemas tradúcese na redución dos mesmos a producir bens e servizos esenciais non só para a conservación da flora e fauna, senón para a propia especie humana. Resulta evidente a necesidade de valorar as externalidades prestadas polos ecosistemas para que a conservación do medio ambiente ocupe un espazo de importancia nas políticas públicas e nos proxectos e toma de decisións transcendentais para o medio natural (Álvarez Vergel et al, 2010).

Existe ademais unha gran cantidade de traballos e publicacións realizados sobre os aproveitamentos e usos do monte que se atopan totalmente dispersos e non accesibles para os propietarios e xestores de terreos forestais (Rigueiro Rodríguez et al, 1997; Carcelén Fernández et al, 1998; Fernández López, 2014; Miranda Fontaíña, 2018; Centro de Investigación Forestal de Lourizán, 2018a; 2018b), que en moitos casos descoñecen posibles alternativas ás usuais plantacións de especies de crecemento rápido con destino de produción de madeira de baixa calidade. A recollida, homoxeneización e divulgación destas posibilidades facilitaría ás comunidades de montes e a outros propietarios forestais o coñecemento para avaliar diferentes posibilidades de uso, para non ter en conta exclusivamente o beneficio económico e incluír dentro das aportacións que pode ofrecer o monte o compoñente social e ambiental. 
Polo tanto, considérase necesario a definición dunha metodoloxía que complemente á lexislación autonómica (Decreto 52/2014, do 16 de abril, polo que se regulan as instrucións xerais de ordenación e de xestión de montes de Galicia, que describe a estrutura e contido mínimo dos proxectos de ordenación forestal), que axude á ordenación dos montes veciñais en áreas naturais e que propoña aproveitamentos alternativos, simulando diversos escenarios que estimen as produtividades e servizos que poderían xerarse no monte atendendo ás superficies que se dediquen a cada uso (madeira, froitos, gando, protección, recreativos, etc.). Esta proposta, que como dixemos tería a súa aplicación no monte veciñal, aportaría unha serie de criterios con maior peso no que se refire ao uso ambiental dos terreos forestais, permitindo integrar máis información no proceso de toma de decisións e asignación de usos potenciais. Aínda que este proxecto se enfoca cara os Montes Veciñais en Man Común, algúns dos seus procedementos e metodoloxías poderían ser válidos noutro tipo de espazos forestais, sempre atendendo ás súas circunstancias particulares.

No seguinte artigo, definiremos algunhas das características fundamentais deste proxecto, analizando os principais postulados do mesmo, as súas vías de traballo ou os seus obxectivos principais. Aínda que se trata dun traballo multidisciplinar con diversos enfoques, excedería os seus límites a explicación sistemática das estratexias de traballo de todas as materias integradas. Polo tanto, vémonos na obriga de focalizarnos nas propostas dun caso concreto: a arqueoloxía e o patrimonio cultural. Optamos por centrarnos nesta disciplina debido ao habitual abandono deste tipo de materias dentro da xestión forestal. Neste sentido, consideramos que ao outorgarlle un peso preponderante dentro deste artigo,estamos a fomentar a visibilización o valor do patrimonio cultural como un ben activo dentro dos recursos potenciais que ofrece o monte. Se ben se trata dun recurso que non adoita proporcionar beneficios materiais "económicos", si que ten un valor único como elemento de cohesión e vertebración entre paisaxe natural e social.

\section{O MARCO DE ACTUACIÓN: UNHA PROPOSTA DE ACTUACIÓN PARA A ORDENACIÓN E XESTIÓN DOS MONTES COMUNAIS}

Dentro das liñas de fomento da innovación e cooperación no ámbito agrario que se está a promover desde a Asociación Europea para a Innovación, creouse a figura dos Grupos Operativos para a Innovación. Estas entidades buscan abordar de forma conxunta un problema concreto ou unha oportunidade nos sectores agroalimentario e forestal, empregando para elo unha idea innovadora; podendo estar constituídos por agricultores, gandeiros, investigadores, centros tecnolóxicos, universidades, organización non gobernamentais, grupos de desenvolvemento rural, asociacións ou outras organismos de interese. Neste marco, considerouse a creación durante o ano 2017 por parte da C.M.V.M.C. Xalo e da Asociación de Desenvolvemento Rural Mariñas-Betanzos do Grupo Operativo "Deseño dunha metodoloxía para a ordenación e xestión de montes veciñais, considerando os 
servizos ecosistémicos producidos". Para a súa constitución, contouse coa participación dos centros de investigación con experiencia e estudios no que respecta á valorización e coñecemento do medio ambiente e patrimonio cultural (Instituto de Biodiversidade Agraria e Desenvolvemento Rural da Universidade de Santiago de Compostela), aproveitamentos agrarios das áreas rurais (Centro de Investigación Agrarias de Mabegondo, Ingacal) e da cartografía e análise territorial galega (Instituto de Estudos do Territorio), en especial no ámbito da Reserva de Biosfera Mariñas Coruñesas e Terras do Mandeo. Ademais contouse co asesoramento e colaboración do gupo de investigación da Universidade de Santiago de Compostela Síncrisis. Investigación en Formas Culturais á hora de coñecer as accións precisas para a análise e estudio do patrimonio histórico e cultural.

En primeiro lugar, esta iniciativa pretende promover unha ordenación dos usos do monte que fomente un aproveitamento multifuncional, considerando os criterios ambientais como unha parte dos recursos a xestionar, integrando a mitigación do cambio climático e a fixación do $\mathrm{CO}_{2}$ como obxectivos fundamentais a ter en conta.

Así mesmo, buscarase a creación dunha ferramenta informática baseada en diversas aplicacións, que axuden a definir e propoñer novos modelos de aproveitamentos forestais e usos alternativos, en detrimento daqueles centrados na produción madeireira, ao mesmo tempo que fomente a cuantificación e valoración dos servizos ecosistémicos que ofrecen. Estas ferramentas informáticas terán como principal obxectivo dar a coñecer os resultados do proxecto e farán accesible toda a información para aquelas persoas ou entidades que estean interesadas.

Por outra parte, resulta esencial plantear unha vía de comunicación entre as comunidades de montes e as liñas de financiamento asociadas á xestión sostible dos terreos forestais (compensación de emisións, custodia cultural, etc.). Un maior coñecemento deste tipo de incentivos axudará a que estes modelos propostos sexan máis atractivos para as Comunidades de Montes.

Nesta liña, a aplicación positiva deste tipo de medidas fomentará que o patrimonio biolóxico e cultural dos montes galegos melloren o seu estado de conservación e valoración.

\subsection{Procedementos e vías de actuación}

Coa intención de crear un marco de traballo que permita coñecer con detalle todas as posibilidades, realizaranse unha serie de entrevistas, tanto a comuneiros como a veciños da zona piloto. Isto permitirá coñecer as variables de maior importancia á hora de valorar e decidir os usos e aproveitamentos a realizar no monte, ao mesmo tempo que permitirá valorar cales son as principais materias de interese para os actores involucrados.

Os integrantes do proxecto conformarán a creación dun comité de expretos, que ademais contará con investigadores e profesionais doutras entidades e da administración de referencia, gardando relación coa xestión foresta e ambiental do territorio (Centro de Investigación Forestal de Lourizán, Augas de Galicia, Dirección Xeral do Patrimo- 
nio Cultural, CSIC-Incipit, Universidade da Coruña, Distrito Forestal, colectivos de comunidades de montes veciñais, etc.). Este comité de expertos permitirá unha correcta coordinación e avaliación dos traballos realizados, avaliaría a viabilidade e aplicación da metodoloxía aplicada e realizará unha supervisión directa da iniciativa, garantindo que se cumpran os obxectivos da mesma. Así mesmo, este comité avaliará o caso real da proba piloto realizada, comprobando a aplicación e funcionalidade as propostas realizadas e analizando e identificando os benefcios que se poderían obter cas diferentes alternativas propostas.

Todos os pasos deste proceso estarán acompañado do uso e xestión de diferentes aplicacións informáticas (follas de cálculo, software SIX), que axudarán tanto á xestión dos datos como á identificación e análise das problemáticas acontecidas, sendo unha parte activa de todo o proceso de recopilación, investigación e difusión da información. Para a aplicación das medidas propostas e a avaliación da valía das mesmas, utilizaranse estas ferramentas para a creación de "simulacións", escenarios alternativos que, atendendo a criterios predefinidos, permitirán analizar, avaliar, interpretar e propoñer diferentes medidas que serán aplicadas ao longo de todo o proxecto. O softtware utilizado será de libre acceso, o que permitirá tanto unha maior versatilidade como unhas maiores facilidades á hora de axilizar e facilitar o acceso libre á información obtida.

Por outra parte, resulta necesario sinalar o eminente carácter multidisciplinar da proposta. Dado que se pretenden analizar e valorar unha gran cantidade de recursos ecosistémicos de índole diversa, resulta imprescindible acudir a múltiples disciplinas e áreas de coñecemento. O carácter interdisciplinar deste proxecto implica atender e integrar a todas estas áreas, orientándoas cara un mesmo fin e aproveitando o potencial que esta tranversalidade investigadora ofrece para obter unha análise moito máis prolífica e detallada.

Tras a creación dun marco institucional e da preparación dos puntos de partida, os primeiros traballos centraranse na caracterización e análise da situación dos montes veciñais das zonas piloto, valorando os seus recursos a nivel ambiental, como se utilizan e cal é o seu plan de ordenación. Identificaranse os usos e aproveitamentos potenciais para cada caso, seleccionando aqueles que semellen máis oportunos, sempre atendendo ás necesidades e intereses dos membros da comunidade, os cales serán involucrados dentro deste proceso a través de múltiples estratexias de participación colectiva.

Tras unha correcta avaliación das posibilidades do monte e das posibles melloras de aproveitamento dos recursos ecosistémicos (sempre seguindo as directrices xerais anteriormente plantexadas), estas proporanse para ser integradas tanto dentro dos plans de ordenación e conservación ambiental, como dentro dos servizos de ecosistemas nas Instrucións Xerais de Ordenación de Montes de Galicia.

Finalmente realizarase unha estratexia de divulgación dos resultados, tanto entre os actores do sector como entre a comunidade científica. Dentro dos plans de divulgación no medio rural, celebraránse varias xornadas de presentación e difusión (tanto para os membros das entidades colaboradoras e participantes, como de acceso libre), así como a divulgación a través de múltiples notas de prensa e artigos de divulgación a través de 
medios e redes informativas enfocados ao ámbito rural e á xestión de recursos agrícolas e forestais (Rede de Asesoramento e Innovación Rural, Asociación Europea da Innovación, etc.). A nivel científico, procederase a difusión a través de diferentes congresos e publicacións de índole científica, buscando contrastar a información recollida con outro tipo de aproximacións metodolóxicas.

Como dixemos anteriormente, estes procedementos son de carácter xeral e deben entenderse como unhas directrices básicas a seguir por todas as disciplinas que forman parte deste proxecto, sempre atendendo ás conxunturas particulares de cada materia. Tal e como veremos no caso da arqueoloxía, estas directrices deben de ser comprendidas como un marco que englobe todas as actuacións e lles outorgue uns obxectivos e unha finalidade conxunta.

\subsection{Zona de traballo}

A zona piloto escollida para a aplicación desta metodoloxía trátase do Monte Veciñal en Man Común Xalo (Culleredo, A Coruña). A nivel ecosistémico, estamos ante unha zona cun gran valor ecolóxico e ambiental, formando parte dunha Reserva da Biosfera e constando dun valor natural moi destacado, coa existencia de especies vexetais e animais endémicas da zona dentro do seu marco xeográfico. Entre os valores naturais máis destacados podemos contemplar a existencia dun hábitat de especial importancia comunitaria, Brezais húmidos atlánticos de zonas templadas de Erica ciliaris e Erica tetralix. Tamén cabe sinalar a identificación de especies destacadas como os anfibios Rana iberica, Rana temporaria e Hyla molleri, ou as aves Tartaraña cincenta (Circus pygargus) e a Rula brava (Streptopelia turtur).

Resulta relevante sinalar que nos atopamos ante unha zona case "virxe" a nivel poboacional, o cal resulta significativo tendo en conta a súa situación en pleno centro da comarca da Coruña, e a escasos quilómetros da propia capital provincial.

A nivel xeográfico, destacamos a situación do Xalo dentro dun macizo granítico montañoso, conformado por granodioritas tardía e precoz. Dentro do seu conxunto, destaca como punto de interese xeolóxico o "Petón do Xalo", un afloramento rochoso conformado por rochas erosionadas de grandes dimensións. O Monte Xalo elévase a 521 metros sobre o nivel do mar, unha altitude moderada, pero única na súa contorna, o que lle outorga unhas características paisaxísticas e microclimáticas únicas, sendo o miradoiro do Golfo Ártabro máis importante pola súa amplitude de visión panorámica, abarcando unha superficie de 64.641 hectáreas (IET, 2017). Estamos, polo tanto, ante un dos puntos máis altos da área da Coruña, expoñéndose como un anfiteatro que contempla toda a área metropolitana da cidade da Coruña.

A nivel hidrográfico, resulta especialmente relevante o nacemento do río Anllóns, que abastece de auga a toda comarca de Bergantiños e á zona norte da Costa da Morte.

A relevancia dos recursos hídricos que contén o Xalo quedan definidos non só por ser o nacemento do rego das Xesteiras, e outros regatos afluentes do río Valiñas, senón 
que no seu ámbito tamén aparece a cabeceira do río Anllóns, que recorre toda a comarca de Bergantiños. A súa riqueza hidrolóxica tamén se contempla nas traídas de augas veciñais existentes e que abastecen de auga aos núcleos rurais das parroquias do sur do concello de Culleredo.

A nivel arqueolóxico e patrimonial, destacamos a presenza de ocupación neolítica, documentando restos de dúas mámoas situadas na súa parte Leste. Por outra parte, tamén se atopan catalogados dous xacementos fortificados de carácter indeterminado, un situado no Petón do Xalo e outro no lugar coñecido como "Castelo da Veiga” (Ferrer Sierra, 2012).

A nivel etnográfico e cultural, o Monte Xalo consta cunha inxente cantidade de lendas e mitoloxías, centradas principalmente na gran cantidade de bolos graníticos existentes nas súas partes máis elevadas, así como fontes, como a "Fonte das Meigas", situada na parte Oeste, ou a "Fonte do Cáliz", situada na parte Leste do Monte Veciñal, na base da Pedra do Castelo. Existía tamén un uso de augas termais ferruxinosas no lugar coñecido como Ternande, na falda orientada ao Oeste do Monte Xalo, que se perdeu pola urbanización da zona.

A responsabilidade da xestión do monte é da CMVMC Xalo, unha comunidade de montes con 310 comuneiros/as que xestiona e posúe 315 ha dentro do ámbito do monte, dentro da parroquia de Celas de Peiro. A xunta reitora desta comunidade leva anos co obxectivo primordial de realizar un aproveitamento multifuncional do monte, onde poidan ter collida usos complementarios e alternativos aos madeireiros tradicionalmente realizados na zona. Coñecedores do importante valor paisaxístico, cultural e natural do monte, buscan realizar unha ordenación que contemple os servizos ecosistémicos e os promova e potencie no futuro.

\section{A ARQUEOLOXÍA E O PATRIMONIO CULTURAL COMO EXEMPLO DE DISCIPLINA INTEGRADA}

Coa intención de exemplificar algunha das propostas de traballo das disciplinas integradas no proxecto, no seguinte punto exporemos brevemente os postulados iniciais dende a arqueoloxía e o patrimonio cultural. Malia que non se trata dunha especialidade que habitualmente teña demasiado peso dentro deste tipo de proxectos, consideramos que as súas propostas amosan con fidelidade os postulados xerais e a "esencia" deste proxecto. Ademais, consideramos que a súa elección é especialmente pertinente para visibilizar os estudos de índole social e das ciencias históricas dentro deste tipo de metodoloxías. Nesta liña, a arqueoloxía e o patrimonio cultural permiten crear vínculos entre a comunidade e o monte, amosando os procesos históricos que os involucraron a ambos de forma conxunta e que permitiu a creación da paisaxe social que actualmente constitúen.

Habitualmente, os bens arqueolóxicos son ignorados, esquecidos ou incluso alterados dentro da xestión forestal, sendo considerados como unha parte irrelevante e carente de interese. Malia este habitual esquecemento, o patrimonio arqueolóxico debe de com- 
prenderse como un recurso máis dos que ofrece o monte, e debe formar parte de calquera marco de actuación que implique a administración destes recursos. Este tipo de proxectos multidisciplinares non só axudan a permitir a súa visibilización, senón que poñen de manifesto a súa relevancia para unha xestión forestal sostible e de calidade.

Seguindo as liñas aportadas polo marco teórico xeral do proxecto, desenvolveranse varios procedementos de actuación que permita unha correcta integración do patrimonio arqueolóxico dentro da xestión do monte, tendo en conta tanto as conxunturas propias de cada espazo como as necesidades da comunidade. Con todo, debemos ter claro que a proposta que aquí expoñemos partirá tanto das directrices marcadas polo plan de actuación xeral como polas circunstancias concretas de estudo e conservación que presenta a zona piloto, e os puntos de partida da mesma deben atender ao estado da investigación da zona en cuestión. Neste sentido, aínda que os postulados xerais desta proposta metodolóxica poidan ofrecer ideas ou metodoloxías con potencial para ser de aplicación xeral, algunhas aproximacións parten das casuísticas particulares da situación do monte a estudar, o que obriga a proceder con cautela e a non extrapolar de xeito sistemático determinados aspectos. No hipotético caso de aplicación deste tipo de metodoloxías noutros exemplos de estudo, débese ter en conta o estado da investigación e as circunstancias particulares de cada área de traballo, e modificala nos casos oportunos.

Con todo, considérase oportuno ter claros dous puntos de partida que deberían resultar comúns a calquera iniciativa que se integre dentro dunha proposta de semellantes características. En primeiro lugar, considérase necesaria a implicación da propia comunidade de montes dentro de todo o proceso de realización dos traballos. O seu compromiso e colaboración resulta esencial para que estes consideren a investigación e os seus resultados como unha parte esencial do monte que poidan recoñecer e coa que sentirse identificados. Ao mesmo tempo, o seu coñecemento da zona en cuestión pode aportar un interesante background contextual que pode facilitar tanto a elaboración de hipóteses coma o traballo de campo.

En segundo lugar, considérase que este tipo de traballos deben partir dende unha visión multidisciplinar da arqueoloxía. Debe aproveitarse a transversalidade da disciplina para aproveitar todo o seu potencial, combinando todas as súas posibles aplicacións para obter un coñecemento arqueolóxico o máis detallado posible. Ignorar ou descoñecer determinadas técnicas e métodos de estudo é unha limitación innecesaria que pode derivar na obtención de información inexacta ou en interpretacións imprecisas.

\subsection{Contexto arqueolóxico}

Atendendo ao estado da investigación e ao coñecemento arqueolóxico dispoñible respecto á zona do Monte Xalo, podemos falar dun bagaxe bastante escaso, mitigado por algunhas obras concretas (Monteagudo Fariña, 1991; Villar Hermida, 1998, así como pola recente realización do PXOM do concello de Culleredo (Ferrer Cruz, 2012), publicacións que aportan algunha información relevante do patrimonio cultural existente na 
zona. Atendendo a estos traballos, documéntase a existencia de 4 xacementos arqueolóxicos dentro da zona de traballo: dúas mámoas e dúas fortificacións sen adscrición cronolóxica clara. Dado o limitado alcance da información dispoñible, as metodoloxías propostas encamiñaranse cara a realización dun primeiro achegamento ao patrimonio arqueolóxico do Monte Xalo de forma conxunta. Os obxectivos propostos son os seguintes:

- Caracterización e interpretación preliminar do patrimonio arqueolóxico da zona, revisando os bens arqueolóxicos inventariados e recoñecendo posibles emprazamentos susceptibles de acoller novos xacementos arqueolóxicos. Para tal fin, aplicaránse diversas técnicas arqueolóxicas non invasivas.

- Estudo e interpretación da paisaxe arqueolóxica da zona de xeito diacrónico, seguindo algunhas metodoloxías de investigación propias da arqueoloxía da paisaxe (Criado Boado, 1999; Parcero Oubiña et al., 1999; García Sanjuan, 2005) e realizando unha interpretación que permita comprender de xeito diacrónico a ocupación humana desenvolvida na zona.

En función dos resultados obtidos, proporanse futuras liñas de investigación e divulgación, atendendo a aqueles puntos que ofrezan un maior interese investigador e divulgativo, e considerando en todo momento os intereses da propia comunidade.

Acadar estes obxectivos permitirá un maior coñecemento arqueolóxico da zona, posibilitando a apertura de novas liñas de investigación e divulgación que, dentro dunha xestión do monte sostible, poden ser de interese mutuo tanto para a comunidade como para o mundo da arqueoloxía.

\subsection{Metodoloxía}

A continuación, analizarase cal será o proceso de traballo a realizar, expoñendo finalmente un exemplo práctico de aplicación das metodoloxías propostas.

\subsubsection{Revisión inicial e puntos de partida}

O método habitual das prospeccións e catalogacións arqueolóxicas adoita partir dunha revisión inicial dos bens arqueolóxicos inventariados na zona en cuestión, revisando as fichas de inventario depositadas na Dirección Xeral de Patrimonio Cultural, toda a bibliografía relevante e aquelos datos toponímicos e etnográficos que poidan considerarse de interese. Este primeiro proceso permitirá realizar unha caracterízación preliminar da zona a estudar, ao mesmo tempo que permitirá definir algúns posibles puntos de interese. Dentro deste procedemento máis "canónico", consideramos relevante incidir na necesidade de fomentar unha relación estreita cos propietarios do monte e coa súa comunidade, atendendo ao xa proposto no punto anterior. A comunidade, ademais de aportar información valiosa sobre a zona, será a que deba ter interese en avaliar e valorar os recursos patrimoniais das súas terras, co que a súa implicación e interese nos traballos resulta clave para que o resultados obtidos sexan incorporados á xestión do monte, así como para que 
ocupen unha posición relevante dentro da mesma.

Así mesmo, a recollida de datos non debe tratarse do paso previo aos traballos de campo, senón como un mero punto de partida inicial que debe de ser completado con outros procedementos, que permitirán adquirir un coñecemento da zona o suficientemente profundo como para realizar un traballo arqueolóxico moito máis certero e eficaz.

\subsection{2. "Prospección arqueolóxica dende o sofá": aplicación de métodos de visualización arqueolóxica baseados en Modelos Dixitais do Terreo}

Aínda que nos últimos anos os traballos con SIX están a experimentar un tremendo auxe dentro da arqueoloxía galega, aínda queda moito camiño por percorrer na súa aplicación práctica. A prospección a través da creación de MDT con datos LiDAR é un paso ineludible se pretendemos realizar unha revisión e catalogación do patrimonio arqueolóxico exitosa.

A metodoloxía a empregar, xa aplicada con éxito noutros casos de estudo (Nión Álvarez, 2018a; 2018b), consiste na creación, visualización e interpretación de MDT e MDE creados a partires de nubes de puntos LiDAR a través de software SIX. Se ben é certo que este tipo de técnicas comezan a difundirse dentro do eido da arqueoloxía de investigación, non son especialmente habituais dentro da arqueoloxía profesional. A aplicación deste tipo de técnicas permite un gran avance para a súa interpretación, ao mesmo tempo que crea múltiples posibilidades para a súa integración dentro da xestión forestal. Os métodos de visualización baséanse principalmente na creación de múltiples shaded relief models de carácter diverso, dentro dos que destacan os seguintes:

- Hillshade, o método de visualización máis común. Utiliza unha técnica de iluminación do MDT que nos permite simular o ángulo de iluminación do so, a elevación da iluminación ou o azimut. Para unha correcta interpretación do terreo, resulta axeitado aplicar varias perspectivas con diferentes parámetros, afinando as características de cada parámetro en relación cos bens arqueolóxicos a documentar.

- Slope gradient, que permite calcular a pendente en cada pixel do MDT. Resulta moi axeitada a súa combinación co hillshade para resaltar varios detalles da topografía do terreo que posibilita unha visualización do mesmo máis detallada.

- Sky-view factor (SVF), que parte da visualización dun MDT con luz difusa (Zakšek et al, 2011). Analiza as diferentes direccións da luz, ao mesmo tempo que mide a porción de ceo visible dende un punto concreto, o que facilita a iluminación das zonas planas, ao mesmo tempo que as depresións escurécense e reciben unha menor cantidade de luz. Adoita ofrecer un maior detalle da superficie topográfica ca os hillshade.

- Simple local relief modelling (SLRM) (Hesse, 2010; Zakšek et al, 2013), unha técnica que realiza unha representación cunha escala local dos valores de eleva- 
ción, o que permite eliminar os elementos morfolóxicos a gran escala e facilita a visibilización de elementos a pequena escala.

- (Positive and negative) Openness (Vletter, 2014), utilizados para analizar a medida angular da relación entre a superficie do relevo e a distancia horizontal. Ao igual ca o SLRM, resultan especialmente útiles para a visualización de elementos a pequena escala.

Esta xestión dos MDT e das diferentes técnicas de visualización debe implicar, de forma inextricable, un fondo coñecemento tanto do rexistro material que se pretende documentar como das formas nas que se pode visibilizar. Debemos ter claro que toda aplicación SIX non é máis ca unha mera ferramenta, e por si mesma nunca proporcionará resultado algún se carecemos dos coñecementos para modelalos, interpretalos e analizalos. Así mesmo, a aplicación destas técnicas será contrastada con outras variables de indubidable valor analítico, como é o caso da comparativa e análise de ortofotos ou do estudo e xeorreferenciación de toponimia.

O traballo con este tipo de técnicas de visualización posibilitará un mellor coñecemento dos bens arqueolóxicos xa catalogados, ao mesmo tempo que permitirá presentar diversos emprazamentos con potencial para acoller xacementos arqueolóxicos. Así mesmo, a precisión xeográfica do software SIX facilitará o estudo en campo das hipóteses de traballo seleccionadas.

\subsubsection{Traballo en campo}

Os dous anteriores puntos son esenciais para crear unha visión de paisaxe conxunta, así como para propoñer novos puntos de partida e recoñecer posibles xacementos descoñecidos sobre o terreo. Sen embargo, estas hipóteses requiren un intenso traballo de campo que permita avaliar a súa validez, así como afinar con máis detalle as súas características. Dende o noso punto de vista, consideramos que este tipo de traballos deben aproveitar a transversalidade da arqueoloxía e das súas disciplinas para aproveitar todo o seu potencial, sexa tanto en campo coma no laboratorio, pois todas teñen unha mesma finalidade: coñecer o noso pasado.

Nesta liña, a nosa proposta metodolóxica baseada na aplicación de técnicas de teledetección con base SIX posibilitará establecer hipóteses de traballo de alta fiabilidade, ao mesmo tempo que permite interactuar de forma case simultánea cun amplo número de variables. Sen embargo, a información que nos aporta debe de ser comprobada e avaliada en campo, amosándonos esta relación simbiótica entre PC e campo que aquí estamos a defender.

Pola súa parte, as metodoloxías arqueolóxicas a aplicar en campo dependerán en boa medida das características e condicións dos bens cos que se traballará. En todo caso, e de forma xeral, ao tratarse dunha prospección arqueolóxica, os traballos estarán encamiñados aos seguintes aspectos: localización de novos xacementos arqueolóxicos e caracterización dos xa coñecidos, definición das características dos sitios documentados, delimitación e xeorreferenciación e propostas de investigación, conservación e divulgación. 


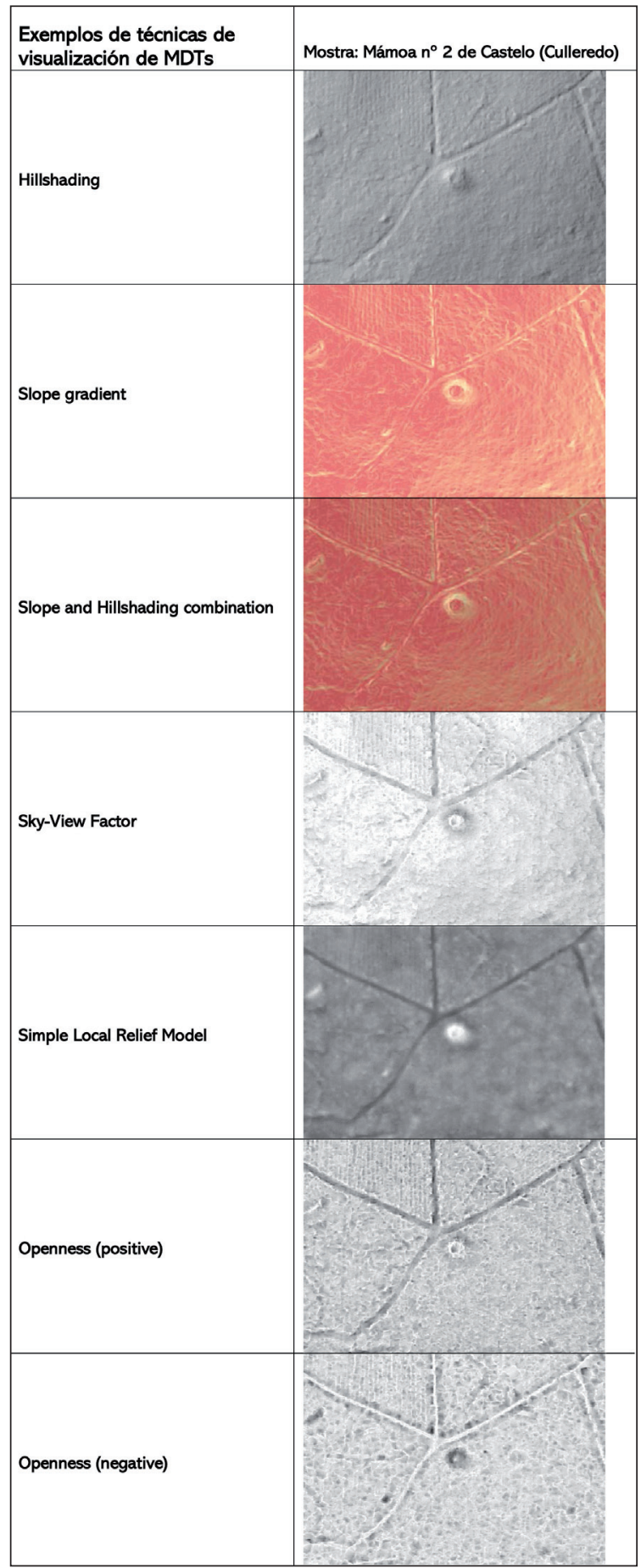

Figura 1. Mostra dalgunhas das técnicas de visualización utilizadas. 


\subsubsection{Síntese, elaboración de propostas e divulgación}

O último paso a seguir será a elaboración dunha síntese xeral, centrada en catro aspectos principais:

- Delimitación, definición e interpretación das zonas arqueolóxicas revisadas.

- Interpretación e caracterización da paisaxe social e da dimensión da ocupación humana no Monte Xalo, creando unha narrativa inicial que permita comprender, grosso modo, as principais características da ocupación humana da zona de xeito diacrónico.

- Elaboración de propostas para a súa correcta integración e conservación dentro da explotación dos recursos ambientais que ofrece o monte.

- Elaboración dun conxunto de medidas de divulgación e visibilización do patrimonio arqueolóxico, coa intención de que forme parte integral do conxunto de medidas propostas para poñer en valor e maximizar os recursos ecosistémicos.

Como plantexamos con anterioridade, o papel da comunidade resulta esencial. Eles deben ser os principais valedores do patrimonio das súas terras, e como tales, deben de formar parte da toma de decisións para conservalo, integralo e visibilizalo dentro da xestión do monte. Deste xeito, as medidas de divulgación propostas para caso serán expostas en común coa comunidade, atendendo ás distintas conxunturas que poden influír en cada cuestión.

\subsubsection{Caso de estudo: A capela de San Bartolomeu e os camiños tradicionais}

Para concluír, amosarase un caso práctico de aplicación desta proposta metodolóxica: a (desaparecida) capela de San Bartolomeu e as rutas de tránsito tradicionais do Monte Xalo. Estamos ante dous exemplos perfectos de como esta conxunción de técnicas e métodos de estudo resulta moi eficaz para a recuperación do patrimonio arqueolóxico. Así mesmo, este tipo de bens arqueolóxicos non adoitan ser receptores en Galicia de plans de posta en valor e de recuperación patrimonial ${ }^{1}$ (con algunha excepción, como pode ser Otero Vilariño, 2003), co que resulta interesante analizar o seu caso para poder explorar outras posibles vías de recuperación e posta en valor do patrimonio arqueolóxico.

Nunha primeira fase preliminar de recollida de documentación, recuperouse certa información relativa a unha fase de ocupación medieval-moderna materializada a través de dous rutas tradicionais, o camiño dos Montañeses e o camiño da Costa.

O camiño dos Montañeses transitaría dende Celas de Peiro ata a Pedra do Coto, atravesando boa parte do Monte Xalo (Villar Hermida, 1998: 26). O Camiño da Costa,

1 A pesar de que coñecemos outros casos nos que os camiños tradicionais son estudados (véxase; Fábrega et al, 2011; Parcero et al, 2013), estes traballos estudan os camiños tradicionais coma un medio para acadar outros obxectivos, non coma un fin de investigación por si mesmo. 
pola súa parte, percorrería dende Altamira ata o val das Encrobas a través do Monte Xalo, pasando pola capela de San Bartolomeu do Vao, a súa fonte e o seu cruceiro (Villar Hermida, 1998: 26). Esta capela estaría citada en diferentes fontes que acreditan a súa existencia entre 1727 e 1822 (Villar Hermida, 1998: 27), ano no que, debido á súa ruína, sería substituída por outra nova edificación situada en Folgueira (Culleredo). Teoricamente, a súa situación estaría na encrucillada de camiños entre o Camiño da Costa e a estrada que parte dela ata a coñecida como Pedra do Castelo (Villar Hermida, 1998: 27). Resulta bastante plausible que boa parte dos seus paramentos fosen transportados e reutilizados para a construción da nova capela, o cal explicaría a ausencia de datos dispoñibles sobre a mesma.

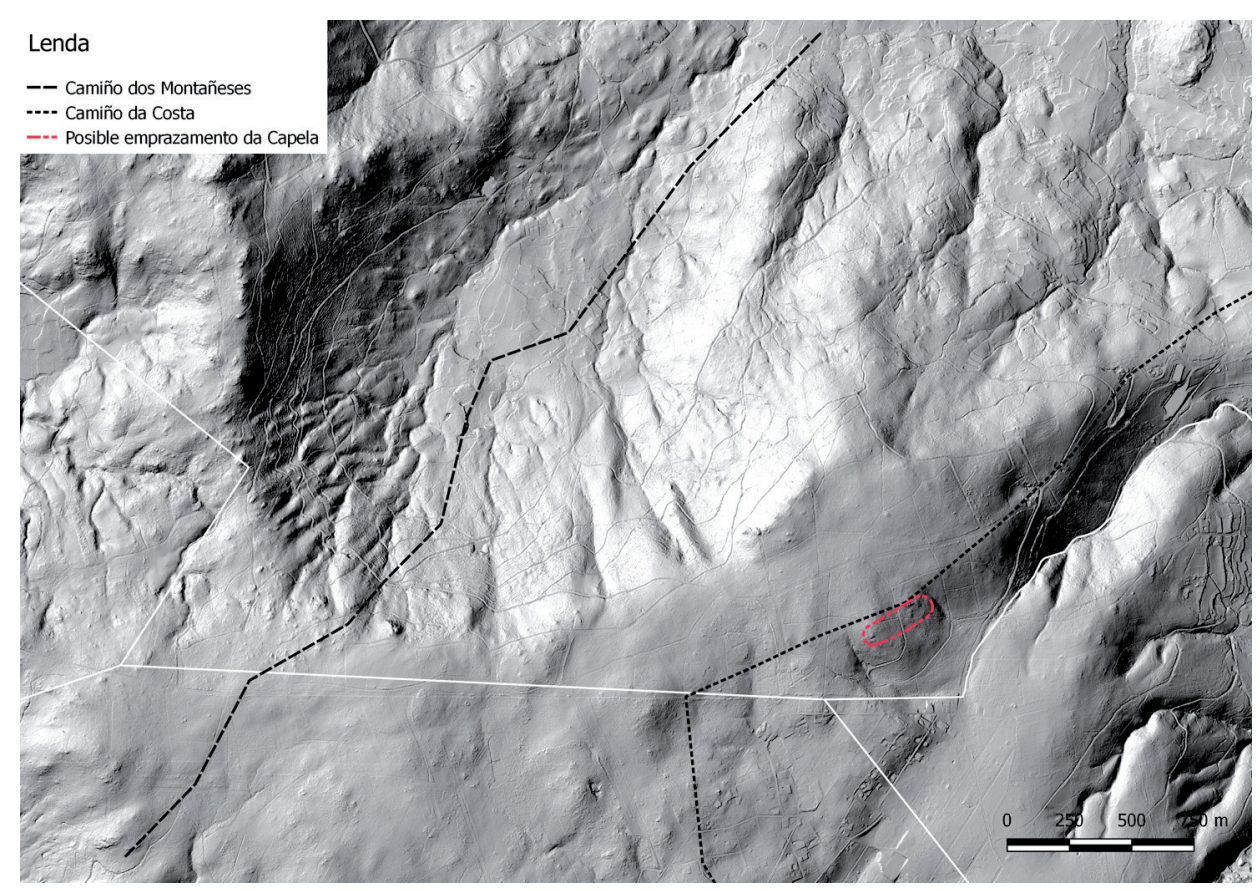

Figura 2. Proposta de localización dos camiños tradicionais do Monte Xalo e da Capela de San Bartolomeu do Vao.

A revisión e análise desta información posibilitará unha modelización e xestión da mesma a través de diferentes técnicas e métodos de estudo, coa intención de documentar e recuperar o posible emprazamento destes bens arqueolóxicos non documentados. Atendendo á diversidade das técnicas de visualización, serán utilizadas diferentes metodoloxías de traballo que, en función das súas características, permiten unha mellor aproximación a cada caso de estudo concreto. En primeiro lugar, para o recoñecemento dos camiños tradicionais optarase por aplicar aquelas técnicas de visualización de MDTs que 
nos permiten recoñecer en superficie a pegada deixada por vagoadas e rutas tradicionais, das que podemos destacar algunhas coma o SLRM ou o positive openness, de validez probada para analizar este tipo de elementos (Vletter, 2014; Small 2016/2017; Herzog, 2017). Como xa explicamos anteriormente, estas técnicas reducen, de xeitos distintos, a morfoloxía xeográfica a gran escala, permitindo poñer o foco de atención en anomalías a pequena escala e facilitando a visibilización de elementos como posibles rutas creadas polo home, que non serían visibles con outras técnicas de visualización. Así mesmo, estes procedementos serán complementados con outros non baseados en MDTs, como pode ser a ortofotografía histórica, o cal permitirá avaliar a pervivencia, características e entidade destes posibles camiños ao longo dos últimos 70 anos.

Pola súa parte, e atendendo ás localizacións para a capela de San Bartolomeu e ás hipóteses plantexadas para o percorrido dos camiños, procederase a analizar as anomalías do terreo a través da aplicación de técnicas de visualización como hillshading, slope gradients ou Sky-View Factor, de indubidable valor para recoñecer estruturas soterradas en superficie (Zaksek et al, 2011; Carrero Pazos et al, 2015). Deste xeito, proporanse diferentes hipóteses para o seu asentamento orixinal, que serán avaliadas na fase de traballo de campo.

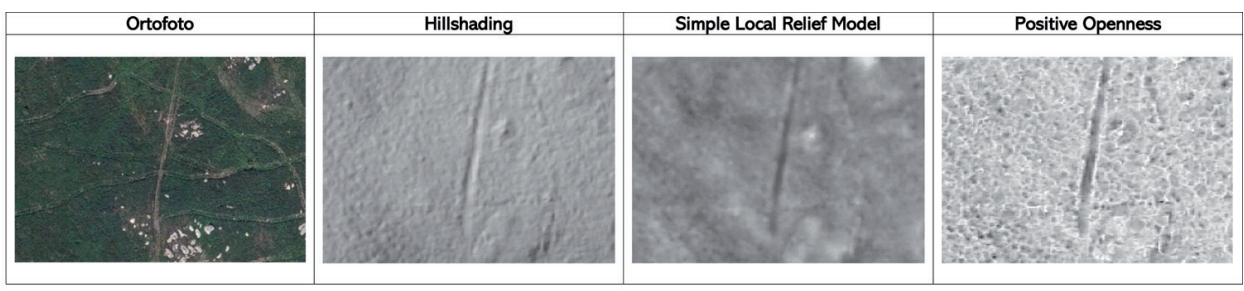

Figura 3. Comparativa de técnicas para visualización de camiños e rutas creadas polo home.

En función dos resultados ofrecidos por esta fase, proporanse diferentes medidas de conservación, investigación, valorización e divulgación dos mesmos. A modo de exemplo, podemos esbozar algunhas posibles propostas (asumindo, de xeito eventual, un resultado positivo das anteriores hipóteses).

O primeiro paso sería a súa integración dentro das habituais rutas de sendeirismo existentes dentro do Monte Xalo. Proporíase unha limpeza da ruta, ao mesmo tempo que se procedería á súa integración dentro do resto de sendeiros e á súa sinalización e identificación a través de diferentes cartaces informativos que ofrezan información sobre os mesmos. Estes poderán completarse tamén con información sobre o patrimonio da zona (tanto arqueolóxico e cultural como biolóxico), en función da localización de cada sitio. Deste xeito, e aproveitando a privilexiada localización da capela dentro da ruta (no caso de ser documentda), esta debería formar parte do propio conxunto, ao mesmo tempo que se poderían aplicar outras metidas alternativas de divulgación e visualización patrimonial, como poden ser a fotogrametría ou a reconstrución virtual en 3D. 
Este tipo de medidas permitirían a integración do patrimonio arqueolóxico dentro da xestión do monte, ao mesmo tempo que se aproveitaría unha actividade moi popular na zona, o sendeirismo, para dar a coñecer o patrimonio cultural a outros sectores da poboación.

\section{CONCLUSIÓNS}

En definitiva, consideramos necesaria a creación de novos marcos administrativos e metodolóxicos que permitan comprender a xestión do monte dende a perspectiva dos servizos ecosistémicos, superando as políticas de explotación do monte encamiñadas unicamente á explotación de madeira. A través deste proxecto, preténdese deseñar unha metodoloxía que permita xerar modelos alternativos de xestión dos terreos forestais en áreas de alto interese ambiental e cultural, que teñan en conta os servizos ecosistémicos producidos e que incorpore criterios ambientais e de loita contra o cambio climático nos plans de ordenación dos montes veciñais.

A súa función non será unicamente a elaboración de escenarios de planificacións para casos concretos ou a simplificación de toma de decisións, senón que se pretende crear unha metodoloxía común que sexa aplicable para os montes veciñais (dos cales existen uns 2800 en Galicia), pero tamén que sente as bases para unha aplicación potencial para os 600000 propietarios de parcelas forestais que existen no noso territorio. Desta forma, iniciaríase a creación dun marco de actución que permita coñecer e definir cada caso concreto, analizando os recursos do monte e as alternativas posibles para a súa xestión.

Nesta liña, consideramos que a arqueoloxía e o patrimonio cultural xogan un papel clave. Na actualidade, podemos albiscar un crecente interese da comunidade no seu patrimonio arqueolóxico e a súa historia, e estes xa non son tan vistos como un estorbo, senón que comezan a ser considerados como unha oportunidade, un nexo de unión con esa paisaxe social da que forman parte e que define a súa identidade persoal. Este tipo de propostas, que comezan a integrar de forma sostible tanto a explotación do monte como a integración do patrimonio, son esenciais para interpretar e valorar os restos arqueolóxicos dentro dun contexto que permita a coexistencia de ambos. 


\section{BIBLIOGRAFÍA}

Álvarez Vergel et al (2010). "Servicios Ambientales en Reserva de la Biosfera Españolas". Ministerio de Medio Ambiente y Medio Rural y Marino. Organismo Autónomo de Parques Nacionales.

Carrero Pazos, M.; Vilas Estévez, B.; Romaní Fariña, E.; Rodríguez Casal, A.A. (2015). "La necrópolis del Monte de Santa Mariña revisitada: aportaciones del Lidar aéreo para la cartografía megalítica de Galicia”. Gallaecia, 34, pp. 39-57.

Carcelén Fernández, E.; Vázquez Fernández, X.G.; López García, J.L.; Barrasa Rioja, M.; Gómez Folgueira, M.; Pereira González, J.M. (1998). Sistema agroalimentario de los pequeños frutos. Frambuesa, zarzamora, arándano y grosella. Proyecto Agrobyte (Universidade de Santiago de Compostela), Santiago de Compostela.

Centro de Investigación Forestal de Lourizán (2018a). Plan de mellora silvícola para plantacións de piñeiro. Consellería de Medio Rural e do Mar (Xunta de Galicia), Santiago de Compostela.

Centro de Investigación Forestal de Lourizán (2018b). Posibilidade de resinación para Pinus pinaster en Galicia”. Consellería de Medio Rural e do Mar (Xunta de Galicia), Santiago de Compostela.

Criado Boado, F. (1999). "Del Terreno al Espacio: Planteamientos y Perspectivas para la Arqueología del Paisaje". CAPA: Cadernos de Arqueoloxía e Patrimonio, 6, pp. 1-90.

FAO (2013). "Los pagos por servicios ecosistémicos”. Organización de las Naciones Unidas para la Alimentación y la Agricultura.

Fábrega Álvarez, P.; Fonte, J.; González García, F.J. (2011). "Las sendas de la memoria. Sentido, espacio y reutilización de las estatuas-menhir en el noroeste de la Península Ibérica". Trabajos de Prehistoria, vol. 68, n 2, pp. 313-330.

Ferrer Sierra, S. (2012). Fichas Inventario Concello de Culleredo (A Coruña). Fichas de inventario depositadas na Dirección Xeral de Patrimonio Cultural, Xunta de Galicia.

Fernández López, J. (2014). Guía de cultivo do castiñeiro para a produción de castaña. Consellería de Medio Rural e do Mar (Xunta de Galicia), Santiago de Compostela.

García Sanjuán, L. (2005). Introducción al reconocimiento y análisis arqueológico del territorio. Ariel, Barcelona.

Institito de Estudios do Territorio (IET). Consellería do Medio Ambiente eo Ordeacíon do Territorio. 2017. Catálogo das Paisaxes de Galicia http://cmaot.xunta.gal/seccionorganizacion/c/CMAOT_Instituto_Estudos_Territorio?content=Direccion_Xeral_ Sostibilidade_Paisaxe/Catalogo_paisaxe_galicia/seccion.html\&std=Visor.html

Herzog, I. "Reconstructing Pre-Industrial Long-distance Roads in a Hilly Region in Germany, Based on historical and Archaeological Data". SDH, vol. 1, 2, pp. 642-660.

Hesse, R. (2010). "LiDAR - Derived Local Relief Models - a New Tool for Archaeological Prospection". Archaeological Prospection, 17, pp. 67-72. 
Monteagudo Fariña, L. (1991). "Necrópolis de mámoas de "A Zapateira" (A Coruña)". Anuario Brigantino, 14, pp. 11-32.

Ministerio de Agricultura y Pesca, Alimentación y Medioambiente. Secretaría General Técnica. (2017). Anuario de Estadística Forestal 2013. Catálogo de Publicaciones de la Administración General del Estado, Madrid.

Miranda Fontaíña, M.E. (2018). A cerdeira galega para madeira: selección, conservación e usos actuais. Consellería de Medio Rural e do Mar (Xunta de Galicia), Santiago de Compostela.

Nión Álvarez, S. (2018a). Prospección e catalogación de xacementos fortificados na provincia da Coruña. Informe valorativo/memoria técnica. Informe/memoria depositado na Dirección Xeral de Patrimonio Cultural, Xunta de Galicia.

Nión Álvarez, S. (2018b). Prospeccións no Concello de Oleiros: Revisión do actual catálogo patrimonial. Informe valorativo/memoria técnica. Informe/memoria depositado na Dirección Xeral de Patrimonio Cultural, Xunta de Galicia.

Otero Vilariño, C. (2003). "Una ruta cultural en Ortegal: O Camiño dos Arrieiros”. TAPA: Traballos de arqueoloxía e patrimonio, 30, pp. 1-65.

Parcero Oubiña, C.; Méndez Fernández, F.; Blanco Rotea, R. (1999). "El registro de la Información en Intervenciones Arqueológicas". CAPA: Cadernos de Arqueoloxía e Patrimonio, 9, pp. 1-86.

Parcero Oubiña, C,; Fábrega Álvarez, P.; Güimil-Fariña, A.; Fonte, J.; Valdez-Tulett, J. (2013). "Castros, caminos, rutas y ocupación del espacio. Modelización y análisis de las formas de movilidad asociadas a los asentamientos de la Edad del Hierro a través de herramientas SIG". En Criado Boado, F.; Martínez Cortizas, A.; García Quintela, M.V. (coord.). Petroglifos, paleoambiente y paisaje. Estudios interdisciplinares del arte rupestre de Campo Lameiro (Pontevedra). CSIC, Madrid.

Ramil Rego, P.; Ferreiro da Costa, J.; de Nóvoa Fernández, B.; Hinojo Sánchez, B., Rubinos Román, M.A. (2011). "Evaluación de servicios de los ecosistemas y biodiversidad en las Reservas de Biosfera de Galicia”. En Fra Paleo, U.; Crecente Maseda, R. (eds.). Las reservas de la biosfera como estrategia territorial de sostenibilidad. Actas del Congreso Internacional. Publicacións da Universidade de Santiago de Compostela, Santiago de Compostela.

Rigueiro Rodríguez, A.; Silva Pando, F.J.; Rodríguez Soalleiro, R.; Castillón Palomeque, P.A.; Álvarez Álvarez, P.; Mosquera Losada, R.; Romero Franco, R.; González Fernández, M.P. (1997). Manual de sistemas silvopastorales. Proyecto Agrobyte (Universidade de Santiago de Compostela), Santiago de Compostela.

Small, F. (2067/2017). "The lost Roman road from Chichester to Arundel". Historic England Research. Uncovering our urban wetlands. Issue 4, pp. 2-8.

TEEB (2010), The Economics of Ecosystems and Biodiversity Ecological and Economic Foundations. Edited by Pushpam Kumar. Earthscan, London and Washington.

Unión Internacional para la Conservación de la Naturaleza (2018). UICN 2017, Informe Anual 2017. UICN, Gland (Suiza). 
Vilar Hermida, X.L. (1998). “As necrópoles de medoñas do Monte Xalo (e arredores)”. Esculca: Sociedade Cultural Museo das Mariñas dos Freires, 4, pp. 24-31.

Vletter, W.F. (2014). "(Semi) automatic extraction for airborne laser scan data of roads and paths in forested areas". Proceedings of SPIE, Second International Conference on Remote Sensing and Geoinformation of the Environment, pp. 1-12.

Zakšek, K.; Oštir, K.; Kokalj, Ž. (2011). "Sky-View Factor as a Relief Visualization Technique". Remote Sensing, 3, pp. 398-415.

Zakšek, K.; Oštir, K.; Kokalj, Ž. (2013). "Visualizations of Lidar Derived Relief Models". En Opitz, R.; Cowley, D. Interpreting Archaeological Topography: Lasers, 3D Data, Observation, Visualization and Applications. Oxford, pp. 100-114. 